\title{
EMERGENCE OF METHICILLIN RESISTANT STAPHYLOCOCCUS AUREUS IN LAOS
}

\author{
MasaAki Iwanaga ${ }^{1,2}$, Lay Sisavath ${ }^{4}$, NaOMi Higa ${ }^{1}$, \\ YASUKO HONMA $^{1}$ AND SHIGE KaKINOHANA ${ }^{3}$ \\ Received April 18, 1997/Accepted August 4, 1997
}

\begin{abstract}
Staphylococcus aureus isolated in Laos (People's Democratic Republic of Lao=Lao PDR) was examined for the drug sensitivities and coagulase type. A total of 114 strains examined consisted of 32 isolated in 1995 and 47 isolated in 1996 from the infection focus, and 35 isolated from nasal mucosa of noninfected patients and nurses working in the wards. One strain with coagulase type IV was regarded as methicillin-resistant S. aureus (MRSA) depending on the minimum inhibitory concentration of the drugs as $>100,100,100,>100$, and $25 \mu \mathrm{g} / \mathrm{m} l$ of methicillin, ampicillin, tetracycline, erythromycin, and cefdinir, respectively. The $m e c A$ gene was detected in this strain but not in the others. This is the first report of MRSA from Lao PDR.
\end{abstract}

\section{INTRODUCTION}

Although methicillin-resistant S. aureus (MRSA) was detected soon after the introduction of methicillin in 1960 (Barrett et al., 1968), a marked rise in the frequency was seen in 1980s. In Japan, increasing of its isolation coincided with increasing use of third-generation cephem antibiotics. Since the late 1980s, more than $50 \%$ of $S$. aureus isolates at the sophisticated hospitals in Japan has been resistant to methicillin. Therefore, the careful use of these antibiotics is now recommended. In contrast, MRSA is rarely isolated in communities where antibiotic use is restricted. In People's Democratic Republic of Lao (Lao PDR), all S. aureus isolated at Mahosot Hospital (the most sophisticated hospital in Lao PDR) in 1993 were sensitive to methicillin (Higa et al., 1994). However, urbanization of Lao PDR, especially Vientiane the Capital of Lao PDR, has been rapidly advanced. And antibiotics are more available in the market. In these situation, the emergence of MRSA should be carefully monitored. In this communication, we described the drug sensitivities and coagulase typing of S. aureus isolated at Mahosot Hospital in 1995 and 1996.

\section{MATERIALs AND MeTHODS}

Bacterial strains: S. aureus isolated at Mahosot
Hospital, Vientiane, Lao PDR was used. The organisms included 79 strains isolated from various clinical specimens in 1995 and 1996, and 32 strains isolated from the nasal mucosa of the staff nurse and in-patients without infectious disease in 1996.

Coagulase typing: Antigenic type of coagulase produced by the isolates was examined by a neutralization test using the Coagulase Typing Immune Sera Kit (Denkaseiken Co. Tokyo). Coagulation inhibition by adding antisera was examined using plastic microdilution plates (Tajima et al., 1992).

Drug sensitivity test: The sensitivities of the isolates against methicillin (DMPPC, Banyu), ampicillin (ABPC, Meiji), tetracycline (TC, Wako), erythromycin (EM, Dainihon), and cefdinir (CFDN, Fujisawa) were examined by using the plate dilution method, and the drug activities against the organisms were expressed by minimum inhibitory concentrations (MICs) of the drug. Twofold dilution series of each antibiotics in heart infusion agar (HIA) were prepared with the drug concentration ranging from 100 to $0.2 \mu \mathrm{g} / \mathrm{m} l$. Cultures of the isolates in heart infusion broth at $37^{\circ} \mathrm{C}$ for $6 \mathrm{hr}$ were diluted 1 to 10 with normal saline solution (ca. $10^{7} / \mathrm{ml}$ ) and were inoculated on the drug-containing HIA plates and drug-free control plates by using Microplanter (Sakuma Co. model MITP \# 00257). MICs of each drug were evaluated after $24 \mathrm{hr}$ incubation at $37^{\circ} \mathrm{C}$. For the sensitivities to methicillin, the concentration of $\mathrm{NaCl}$ in

\footnotetext{
1 Department of Bacteriology, 2 Research Center of Comprehensive Medicine, 3 Department of Fundamental Nursing, Faculty of Medicine, University of the Ryukyus, 207 Uehara, Nishihara, Okinawa 903-01, Japan

4 National Institute of Hygiene and Epidemiology, Vientiane, Lao People's Democratic Republic
} 
drug-containing HIA was adjusted to $4 \%$, and the culture was carried out at $30^{\circ} \mathrm{C}$ for $24 \mathrm{hr}$.

Detection of mecA gene: $\operatorname{mec} A$ was detected by using PCR analysis. The 24-hour cultured colonies on nutrient agar plates were suspended in distilled water and then boiled for $20 \mathrm{~min}$, which was regarded as the samples for DNA of interest. The PCR primers used for detecting mecA were 5'-GAACCTCTGCTCAACAAGTT-3' and 5'-GGATTTGCCAATTAAGTTTG-3' as described by Song et al. (1987) and re-examined by Muraki et al. (1993). These were designed to amplify a 630 bp fragment derived from a portion of the mecA gene encoding PBP2' which has been shown to be the entity of MRSA.

\section{RESULTS}

Coagulase type: The distribution of coagulase type varied, but type $\mathrm{V}$ was predominant. In 1996, $63.8 \%$ of the isolates from infection sites revealed type $\mathrm{V}$ but only $28.6 \%$ from the nasal mucosa of non-infective individuals. Type II strains were found in $4.3 \%$ of the isolates from the infection, whereas $25.7 \%$ from the nasal mucosa of non-infected individuals.

Drug sensitivities: Generally, the isolates showed good susceptibilities against the drugs examined. A few strains were highly resistant to erythromycin. The MIC of methicillin was $6.25 \mu \mathrm{g} / \mathrm{m} l$ or less against almost all

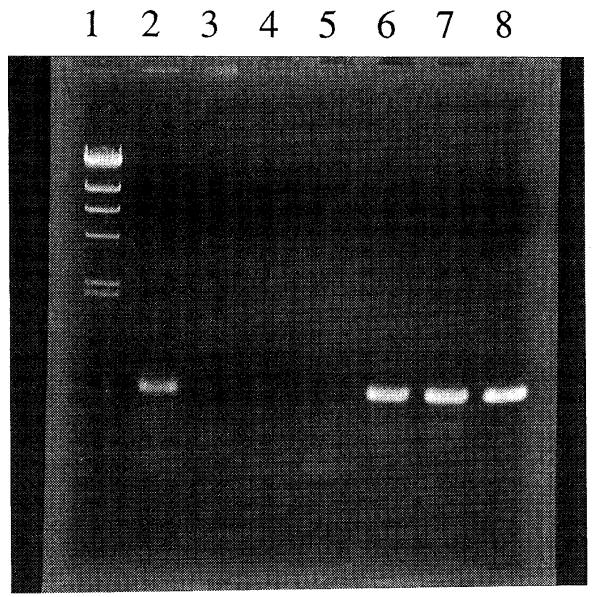

Figure $1630 \mathrm{bp}$ fragment of $m e c A$ gene detected as the PCR product. Lanes: $1=$ molecular marker, $2=\mathrm{LC} 13$ ( $>$ $100 \mu \mathrm{g} / \mathrm{m} l$, MRSA $), 3=\mathrm{LC} 18(12.5 \mu \mathrm{g} / \mathrm{m} l), 4=$ 95P1 $(6.25 \mu \mathrm{g} / \mathrm{m} l), 5=96 \mathrm{P} 5(12.5 \mu \mathrm{g} / \mathrm{m} l), 6=\mathrm{R} 1$ $(>100 \mu \mathrm{g} / \mathrm{m} l), 7=\mathrm{R} 4(100 \mu \mathrm{g} / \mathrm{m} l), 8=\mathrm{R} 12(>100$ $\mu \mathrm{g} / \mathrm{m} l)$. MICs of methicillin to each strain were indicated in parenthesis. Lanes 2 to 5 are of Lao strains and lanes 6 to 8 are of Japanese strains. Only one Lao strain (LC13) of 114 examined was positive for mecA. isolates, the growth of 3 isolates were inhibited at 12.5 $\mu \mathrm{g} / \mathrm{m} l$ or more, and 1 of them was resistant to methicillin at $100 \mu \mathrm{g} / \mathrm{m} l$. MICs of the other drugs against the 2 isolates were 0.8 and $3.13 \mu \mathrm{g} / \mathrm{m} l$ of $\mathrm{ABPC}$, $\leqq 0.2$ and 0.8 $\mu \mathrm{g} / \mathrm{m} l$ of $\mathrm{CFDN}, \leqq 0.2$ and $0.4 \mu \mathrm{g} / \mathrm{m} l$ of $\mathrm{TC}$, and $>100$ and $\leqq 0.2 \mu \mathrm{g} / \mathrm{m} l$ of EM, respectively. MICs of the one isolate resistant to DMPPC at $100 \mu \mathrm{g} / \mathrm{m} l$ were $100 \mu \mathrm{g} /$ $\mathrm{m} l$ of $\mathrm{ABPC}, 25 \mu \mathrm{g} / \mathrm{m} l$ of $\mathrm{CFDN}, 100 \mu \mathrm{g} / \mathrm{m} l$ of TC, and $>100 \mu \mathrm{g} / \mathrm{m} l$ of EM. Coagulase type of this strain was type IV. These results are summarized in Tables 1 , $2,3$.

Detection of $m e c A$ gene: All isolates except one were negative for mecA. Only one strain, against which the MIC of methicillin was $>100 \mu \mathrm{g} / \mathrm{m} l$, possessed the gene (Fig. 1).

Table 1 Drug sensitivities and coagulase type

\begin{tabular}{cccccc}
\hline MIC $(\mu \mathrm{g} / \mathrm{m} l)$ & DMPPC & ABPC & TC & EM & CFDN \\
\hline$\leqq 0.2$ & 0 & 6 & 9 & 27 & 11 \\
\hline 0.39 & 0 & 0 & 0 & 2 & 16 \\
\hline 0.78 & 0 & 4 & 0 & 0 & 4 \\
\hline 1.56 & 1 & 2 & 0 & 0 & 0 \\
\hline 3.13 & 19 & 12 & 0 & 0 & 0 \\
\hline 6.25 & 12 & 6 & 7 & 0 & 0 \\
\hline 12.5 & 0 & 2 & 8 & 0 & 0 \\
\hline 25 & 0 & 0 & 8 & 0 & 0 \\
\hline 50 & 0 & 0 & 0 & 0 & 1 \\
\hline 100 & 0 & 0 & 0 & 0 & 0 \\
\hline$>100$ & 0 & 0 & 0 & 3 & 0 \\
\hline
\end{tabular}

\begin{tabular}{cccccccccc}
\hline coagulase type & I & II & III & IV & V & VI & VII & VIII & UT \\
\hline No. of strains & 0 & 7 & 1 & 1 & 16 & 1 & 5 & 0 & 1 \\
\hline \multicolumn{1}{c}{32 isolates from infection focus } & $(1995)$
\end{tabular}

Table 2 Drug sensitivities and coagulase type

\begin{tabular}{cccccc}
\hline $\mathrm{MIC}(\mu \mathrm{g} / \mathrm{m} l)$ & DMPPC & ABPC & TC & EM & CFDN \\
\hline$\leqq 0.2$ & 0 & 1 & 24 & 16 & 32 \\
\hline 0.39 & 0 & 0 & 1 & 1 & 14 \\
\hline 0.78 & 0 & 4 & 0 & 23 & 1 \\
\hline 1.56 & 4 & 31 & 0 & 6 & 0 \\
\hline 3.13 & 23 & 8 & 0 & 0 & 0 \\
\hline 6.25 & 19 & 0 & 0 & 0 & 0 \\
\hline 12.5 & 1 & 0 & 5 & 0 & 0 \\
\hline 25 & 0 & 2 & 10 & 1 & 0 \\
\hline 50 & 0 & 0 & 7 & 0 & 1 \\
\hline 100 & 0 & 1 & 0 & 0 & 0 \\
\hline$>100$ & 0 & 0 & 0 & 3 & 0
\end{tabular}

\begin{tabular}{cccccccccc}
\hline coagulase type & I & II & III & IV & V & VI & VII & VIII & UT \\
\hline No. of strains & 0 & 2 & 4 & 2 & 30 & 0 & 3 & 1 & 5 \\
\hline
\end{tabular}

47 isolates from infection focus (1996) 
Table 3 Drug sensitivities and coagulase type

\begin{tabular}{cccccc}
\hline MIC $(\mu \mathrm{g} / \mathrm{m} l)$ & DMPPC & ABPC & TC & EM & CFDN \\
\hline$\leqq 0.2$ & 1 & 3 & 18 & 30 & 14 \\
\hline 0.39 & 0 & 1 & 0 & 1 & 19 \\
\hline 0.78 & 1 & 5 & 0 & 0 & 0 \\
\hline 1.56 & 3 & 6 & 0 & 0 & 1 \\
\hline 3.13 & 24 & 13 & 1 & 0 & 0 \\
\hline 6.25 & 4 & 3 & 7 & 0 & 0 \\
\hline 12.5 & 1 & 2 & 5 & 0 & 0 \\
\hline 25 & 0 & 0 & 3 & 0 & 1 \\
\hline 50 & 0 & 1 & 0 & 0 & 0 \\
\hline 100 & 0 & 1 & 1 & 1 & 0 \\
\hline$>100$ & 1 & 0 & 0 & 3 & 0 \\
\hline
\end{tabular}

\begin{tabular}{lccccccccc}
\hline coagulase type & I & II & III & IV & V & VI & VII & VIII & UT \\
\hline No. of strains & 0 & 9 & 4 & 2 & 10 & 0 & 5 & 2 & 3 \\
\hline \multicolumn{1}{c}{35 isolates from nasal mucosa } & $(1996)$
\end{tabular}

\section{DISCUSSION}

MRSA is a major organism involved in nosocomial infection. It is recognized that the increased isolation frequency of MRSA is associated with the use of antibiotics, especially the third generation cephems. We examined S. aureus isolated in Lao PDR in 1993, and MRSA was not found (Higa et al., 1994). According to the hospital and drug stores in the city (we got the information through the questionaire), the restricted kinds and amount of antimicrobials such as penicillin $(G$ and $\mathrm{V}$ ), ampicillin, tetracycline, gentamicin, erythromycin, sulfamethoxazol-trimethoprim compound and nalidixic acid, were used in the country before 1993. However, since then, the types and amount of consumed antimicrobials increased with amoxicillin, chloramphenicol, cloxacillin, doxycycline, lincomycin, and ofloxacin. The drug susceptibility of $S$. aureus looks getting resistant little by little. All 54 isolates from the infection focus in 1993 were inhibited by methicillin at the concentration of $6.25 \mu \mathrm{g} / \mathrm{m} l$ including $7 \%$ of the isolates inhibited at $6.25 \mu \mathrm{g} / \mathrm{m} l$, and most strains were inhibited at $3.13 \mu \mathrm{g} / \mathrm{ml}$. However, $37 \%$ of the 32 isolates in 1995 were inhibited at $6.25 \mu \mathrm{g} / \mathrm{m} l$, and there was no strain to which the MIC of methicillin was $12.5 \mu \mathrm{g} / \mathrm{ml}$ or more. In $1996,42 \%$ of the 47 isolates were inhibited at $6.25 \mu \mathrm{g} /$ $\mathrm{m} l$ or more, including one strain inhibited at $12.5 \mu \mathrm{g} / \mathrm{m} l$ of methicillin. However, the 35 isolates (in 1996) from non-infected patients and the nurses working at the wards included 4 strains (11\%) inhibited at $6.25 \mu \mathrm{g} / \mathrm{ml}$, one strain at $12.5 \mu \mathrm{g} / \mathrm{m} l$, and one highly resistant strain (resistant at $100 \mu \mathrm{g} / \mathrm{m} l$ ). This highly resistant strain possessing $m e c A$ gene is the first reported MRSA in Lao PDR.

The coagulase types of MRSA recently isolated in Japan were mostly type II, but that of the first reported MRSA from Lao PDR was type IV. It reminds us of the fact that, in the beginning of 1980s when the problem of MRSA was recognized in Japan, the coagulase type of MRSA was mainly type IV (Matsumoto et al., 1984). The small percentage of coagulase type II in Lao PDR may be due to the rare occurrence of MRSA at present in this country.

This emergence of MRSA in Lao PDR is likely a result of the increased use of a various antimicrobials. In this study, only one isolate of MRSA was found in a non-infective patient, but not in the patient with Staphylococcal infection. It may be due to small number of parameter (Number of Patient examined), because the isolation frequency of drug resistant organism supposed to be higher in the patients with antibiotic treatment than those without antibiotics. Therefore, it is now important to start surveillance to control MRSA in this country.

\section{ACKNOWLEDGEMENTS}

We thank the staff of Mahosot Hospital for collecting bacterial strains.

\section{REFERENCES}

1) Barrett, F.F., McGehee, R.F. and Finland, M. (1968): Methicillin-resistant Staphylococcus aureus at Boston City Hospital. New Engl. J. Med., 279, 441-448

2 ) Higa, N., Sithivong, N. and Iwanaga, M., (1994): A comparative study on Staphylococcus aureus isolated in Lao PDR and in Japan. Jpn. J. Trop. Med. Hyg., 22, 129-131

3 ) Matsumoto, K., Kudo, K., Uzuka, Y., Watanabe, K., Nagatake, T., Rikitomi, N., Takahashi, A. and Suzuki, H. (1984): The pathogenic strains of Staphylococcus aureus lately isolated in Japan. Chemotherapy, 32, 527533

4) Muraki, C., Taishi, K., Yamashita, K., Otsuka, N., Kagawa, S. and Matsuoka, A. (1993): Detection of methicillin-resistant Staphylococcus aureus using PCR and non-radioactive DNA probes. Jpn. J. Clin. Pathol., 41, 1159-1166

5 ) Song, M. D., Wachi, M., Doi, M., Ishino, F. and Matsuhashi, M. (1987): Evolution of an inducible penicillintarget protein in methicillin-resistant Staphylococcus aureus by gene fusion. FEBS lett., 167-171

6 ) Tajima, Y., Nagasawa, Z., Tanabe, I., Yamada, H., Kusaba, K., and Tadano, J. (1992): An improved 
method for the serotyping of free coagulase from Sta

phylococcus aureus. Microbiol. Immunol., 36, 1233-1237 